\title{
Investigation of glazed pottery fragments (XIX century A. D.) from Agsu site (Azerbaijan) by XRF and Raman techniques
}

\author{
Valentina Venuti, ${ }^{1,}$, Vincenza Crupi $^{2}$, Barbara Fazio ${ }^{3}$, Giuseppe Paladini ${ }^{1}$, Mauro Francesco La Russa ${ }^{4}$, Michela Ricca $^{4}$, \\ Natalia Rovella ${ }^{4}$, Andrea Macchia ${ }^{5}$, Fariz Khalilli ${ }^{6}$, and Domenico Majolino ${ }^{1}$ \\ ${ }^{1}$ Dipartimento di Scienze Matematiche e Informatiche, Scienze Fisiche e Scienze della Terra, Università degli Studi di Messina, Viale \\ Ferdinando Stagno d'Alcontres 31, 98166 S. Agata, Messina, Italy \\ ${ }^{2}$ Dipartimento di Scienze Chimiche, Biologiche, Farmaceutiche ed Ambientali, Università degli Studi di Messina, Viale Ferdinando \\ Stagno d'Alcontres 31, 98166 S. Agata, Messina, Italy \\ ${ }^{3}$ CNR-IPCF Istituto per i Processi Chimico Fisici, Viale Ferdinando Stagno d'Alcontres 37, 98158 Faro Superiore, Messina, Italy \\ ${ }^{4}$ Dipartimento di Biologia, Ecologia e Scienze della Terra, Università degli Studi della Calabria, Via Pietro Bucci, 87036 Arcavacata di \\ Rende, Cosenza, Italy \\ ${ }^{5}$ YOuth in COnservation of CUltural Heritage, YOCOCU, 00175 Rome, Italy \\ ${ }^{6}$ MIRAS Social Organization in Support of Studying of Cultural Heritage, AZ 1001 Baku, Azerbaijan
}

\begin{abstract}
In this study a multi-technique analysis was performed on the decorated surfaces of four ancient pottery fragments dated back XIX century A.D. withdrawn from the archaeological site of the medieval Agsu town, in Azerbaijan. During the last decade, the site underwent to an extensively archaeometric investigation by means of different non-destructive, or microdestructive, techniques. In this work we focused our attention on the characterization of the pigmenting agents and glazes at different spatial scales from elemental to microscopic domain by using portable and not-portable equipments. In particular, the elemental and molecular compositions were successfully determined by X-ray fluorescence (XRF) and Raman spectroscopy, respectively. On one side, data deriving from portable instrument were compared with those previously obtained from not-portable approach, in view of future in situ investigations. On the other side, the overall obtained results appear crucial for the reconstruction of the production technology used by craftsman of the past.
\end{abstract}

\section{Introduction}

Characterization of pottery fragments withdrawn from archaeological excavations represents still a challenging task in archaeometry $[1,2]$. This because of the large variety of minerals composing the material and due to the extremely complex design of the firing process adopted by artisans. When the investigated fragment shows a decorated surface, the analysis of the chemical composition is even more hard to carry out because of the difficulty to differentiate the external glazed/coloured surface from the underlying bulk ceramic paste. In addition, the high temperature achieved during the firing process could lead to the establishment of chemical reactions which modify the chemical composition and create new layer between each interface. However, knowledge of chemical/physical properties of potteries represents a fundamental prerequisite in order to get information about artistic and technological development of a specific population, associated to a particular historical/geographical context [3-5]. As widely reported, their characterization is hopefully based on the use of non-invasive or, at least, micro-destructive multitechnique approaches, in order to preserve the integrity of the artefact [6-9].
The medieval Agsu site ( $19^{\text {th }}$ century) is an extended archaeological excavation placed $160 \mathrm{~km}$ west far from Baku, the Azerbaijans' capital. Specifically, it is situated in the south-est area of the Agsu town, and during the early stage of the medieval period it was considered as an important settlement for heritage trades as well as crossroad for commercial routes between Europe and Asia. Since the first archaeological excavation in 1983, a great variety of different artefacts was disclosed including coins, glazed potteries and earthenware [10]. This testifies the connection of Agsu with several countries and cities around the world. The town was repeatedly subjected to attacks and depreciations, which is the reason why it is extremely fortified by walls and defensive towers.

The site remained almost unexplored from the archaeometric point of view until few years ago, when an extensive scientific investigation, both in situ and in laboratory, started. The present study is a prosecution of a wide research carried out at different spatial regimes, from elemental to molecular level, on artefacts coming from this site. Firstly [11], optical microscopy (OM), scanning electron microscopy-energy dispersive spectroscopy (SEM-EDS), X-ray diffraction (XRD), and prompt gamma activation analysis (PGAA), allowed a 
grouping of the analyzed samples, based on petrographic and compositional features. Subsequently [12], Rutherford Backscattering Spectrometry (RBS), ProtonInduced X-ray Emission (PIXE) spectroscopy, ionmicrobeam analysis and synchrotron radiation (SR) Fourier transform infrared (FTIR) microspectroscopy were applied to gain crucial information regarding the provenance and the firing technology of the shards. SRFTIR technique, in particular, allowed the identification of pigments and binders used for the pottery production.

Aim of the present work is, on one side, the definition of the elemental composition of selected pottery fragments by using a handheld X-ray fluorescence (XRF) spectrometer. We decided to adopt this non-invasive methodological approach in order to compare data obtained with portable instrumentation with those collected in previous elemental characterizations through not-portable benchtop spectrometers and/or available at Large Facilities. This could prove the reliability of the reported data, and hence of the followed approach, in view of future studies that will be performed in situ on unmovable archaeological objects.

On the other side, the molecular composition of pigments and, for the first time, of the glazes was attempted by a non-invasive approach complementary to SR-FTIR, i.e. by using Raman spectroscopy, and exploring wavenumber ranges well below the mid infrared (MIR) region.

\section{Materials and methods}

\subsection{Materials}

Four decorated pottery fragments taken from the medieval ruins of Agsu, labelled as AZR3, AZR5, AZR7 and AZR1, were analysed. They presumably belong to objects of domestic provenance such as vessels or bowls (see Fig. 1).
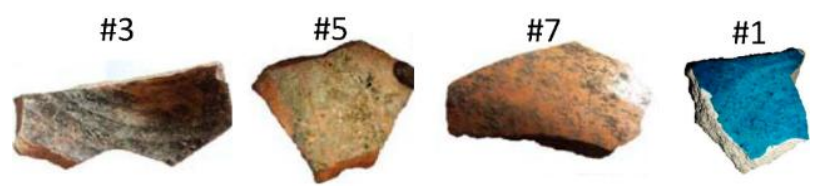

Fig. 1. Decorated pottery fragments withdrawn from the Agsu site.

At a first glance, all samples show a uniform ceramic body and a homogeneous glazed layer of different shades. The shards have been selected as representative of two different groups, namely Group 1 and Group 2, recognized in our previous study [11], according to their macroscopic features and petrographical characteristics. In particular, samples AZR3, AZR5 and AZR7 belong to Group 1, sample AZR1 to Group 2. Typology and description of the investigated potteries are reported in Table 1 .

Table 1. Investigated samples, typology and related description.

\begin{tabular}{|c|c|c|}
\hline Sample & Typology & Description \\
\hline AZR3 & Glazed pottery & $\begin{array}{c}\text { Dark beige ceramic } \\
\text { body, black glaze }\end{array}$ \\
\hline AZR5 & Glazed pottery & $\begin{array}{c}\text { Reddish ceramic } \\
\text { body, dark yellow } \\
\text { glaze }\end{array}$ \\
\hline AZR7 & Glazed pottery & $\begin{array}{c}\text { Reddish ceramic } \\
\text { body, yellowish } \\
\text { glaze }\end{array}$ \\
\hline AZR1 & Faience & $\begin{array}{c}\text { White ceramic } \\
\text { body, light blue } \\
\text { glaze }\end{array}$ \\
\hline
\end{tabular}

\subsection{Methods}

XRF measurements were carried out by a portable XRF "alpha 4000" (Innovex-X system) analyzer that allowed the detection of chemical elements having an atomic number $(Z)$ between phosphorus and lead. It is equipped with a Ta anode X-ray tube as source and a Si PIN diode (active area of $170 \mathrm{~mm}^{2}$ ) as detector. For each sample, two sequential tests were performed: the first with operating condition of $40 \mathrm{kV}$ and $7 \mu \mathrm{A}$ and the second with $15 \mathrm{kV}$ and $5 \mu \mathrm{A}$, for a total collection time of $120 \mathrm{~s}$. According to this, we were able to detect elements from $\mathrm{P}$ to $\mathrm{Pb}$. The instrument was controlled thanks to a Hewlett-Packard iPAQ Pocket PC which was used also as data storage. Calibration was performed by soil LEAP II and was verified using alloy certified reference materials produced by Analytical Reference Materials International. The XRF signal was then collected for about 60 s per run in such a way to get a better statistic. For all the investigated samples, the lines detected at $8.15 \mathrm{keV}$ and $\sim 9.34 \mathrm{keV}$ have been associated to the $\mathrm{L}_{\alpha}$ and $\mathrm{L}_{\beta}$ transitions of Ta anode.

Micro-Raman spectra were collected, in non-invasive way, by means of a LabRam HR800 Raman confocal Micro-Spectrometer (Horiba-Jobin Yvon) in the backscattering configuration. The instrument is equipped with several type of excitation laser including a $\mathrm{He}-\mathrm{Ne}$ laser at $633 \mathrm{~nm}$, an argon ion laser used to produce the UV line at $364 \mathrm{~nm}$, a solid-state laser at $561 \mathrm{~nm}$, and a diode laser at $785 \mathrm{~nm}$. The laser beams are focused by means of a microscope objective $50 \times$ Long Working Distance (Olympus LM-Plan-Fl, NA $=0.5$, power of 0.5 $\mathrm{mW}$ on samples) mounted on an Olympus BX41 microscope. During the measurements, the scattered radiation was dispersed by a $600 \mathrm{1} / \mathrm{mm}$ grating and collected by a silicon CCD as a detector (Synapse, Horiba-Jobin Yvon). In our study, we chose the excitation wavelength $\left(\lambda_{\text {exc }}\right)$ which gave for each sample the best Raman response, in order to overcome problems arising from fluorescence contribution to the spectrum. For each spectrum showed in the Results and discussion section, the chosen wavelength is reported in the corresponding figure caption.

For a reliable assignment of the observed vibrational bands, the obtained spectra were compared with those of various databases and literature [13, 14].

\section{Results and discussion}


XRF spectra collected on the glazed decorated surfaces of the four investigated fragments are reported in Fig. 2(a-d).
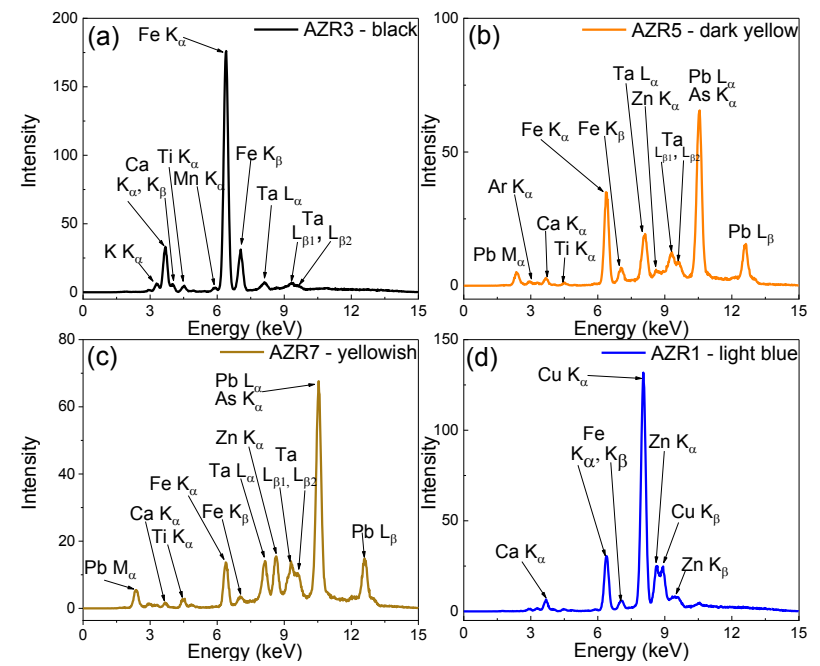

Fig. 2. XRF spectra, collected in the $0-14 \mathrm{keV}$ range, on (a) the black glazed surface of sample AZR3, (b) the dark yellow glazed surface of sample AZR5, (c) the yellowish glazed surface of sample AZR7, and (d) the light blue glazed surface of sample AZR1.

The elemental composition, as obtained by the XRF spectral analysis, is summarised in Table 2.

Table 2. Elements detected by X-Ray fluorescence analysis. For each sample, the key element for pigment identification is marked in bold. The minor or trace elements are presented between brackets.

\begin{tabular}{|c|c|c|}
\hline Sample & Analysed Area & $\begin{array}{c}\text { Detected Elements by } \\
\text { XRF }\end{array}$ \\
\hline AZR3 & Black glaze & $\begin{array}{c}\mathrm{Ca}, \mathbf{F e}, \mathrm{K}(\mathrm{Ti}, \mathrm{Mn}, \mathrm{Sr}, \mathrm{Ba}, \\
\mathrm{Zn}, \mathrm{Cr}, \mathrm{Zn})\end{array}$ \\
\hline AZR5 & $\begin{array}{c}\text { Dark yellow } \\
\text { glaze }\end{array}$ & $\begin{array}{c}\mathrm{S}, \mathrm{Pb}, \mathrm{Cl}, \mathrm{As}, \mathbf{F e}(\mathrm{Ca}, \mathrm{K}, \\
\mathrm{Cu}, \mathrm{Zn}, \mathrm{Ti}, \mathrm{Sn}, \mathrm{Cd}, \mathrm{Sb})\end{array}$ \\
\hline AZR7 & Yellowish glaze & $\begin{array}{c}\mathrm{S}, \mathbf{P b}, \mathrm{Cl}, \mathrm{As} \mathrm{Zn}, \mathbf{F e}, \mathrm{Ti}, \\
\mathrm{Ca}, \mathrm{Ba}, \mathrm{Se}, \mathrm{Cd}, \mathrm{Ag}, \mathrm{Mn})\end{array}$ \\
\hline AZR1 & Light blue glaze & $\begin{array}{c}\mathrm{Cu}, \mathrm{Ca}(\mathrm{K}, \mathrm{Fe}, \mathrm{Cl}, \mathrm{Pb}, \mathrm{Ti}, \\
\mathrm{Ba}, \mathrm{As}, \mathrm{Mn}, \mathrm{Sr}, \mathrm{Sn}, \mathrm{Cr}, \\
\mathrm{Zr})\end{array}$ \\
\hline
\end{tabular}

In the case of AZR3 fragment, the simultaneous observation of the high peaks associated to the $\mathrm{K}_{\alpha}(\sim$ $6.40 \mathrm{keV})$ and $\mathrm{K}_{\beta}(\sim 7.06 \mathrm{keV})$ transitions of iron $(\mathrm{Fe})$, together with that related to the $\mathrm{K}_{\alpha}$ transition of manganese $(\mathrm{Mn})(\sim 6.40 \mathrm{keV})$ suggests the use of a mixture of iron oxides and manganese oxides for the black coloration. No more detailed information on the composition of the glaze were obtained, being this latter seriously damaged.

The XRF spectra of the dark yellow glazed surface of AZR5 fragment and yellowish surface of AZR7 (Fig. 2 (b) and (c), respectively) appear quite comparable, revealing an overall similar elemental composition. The detection of the $\mathrm{L}_{\alpha}(\sim 10.54 \mathrm{keV})$ and $\mathrm{L}_{\beta}(\sim 12.60 \mathrm{keV})$ transition lines associated to lead $(\mathrm{Pb})$ furnishes a clear indication of the use of $\mathrm{Pb}$-oxides for the glaze, whereas the yellowish and dark yellow colorations of the underlying pigmented layers are probably due to ironoxides.

Finally, as far as the XRF spectrum of AZR1 sample is concerned, the presence of intense peaks at $\sim 8.04 \mathrm{keV}$ and $\sim 8.90 \mathrm{keV}$, respectively associated to the $\mathrm{K}_{\alpha}$ and $\mathrm{K}_{\beta}$ transition lines of copper $(\mathrm{Cu})$, suggests the use of a $\mathrm{Cu}$ based pigment for the blue coloration. Furthermore, the detection of calcium $(\mathrm{Ca})$ and lead $(\mathrm{Pb})$ indicates a glassy layer made up of a mixture of $\mathrm{Ca}$ - and $\mathrm{Pb}$-based chemical composites. Traces of zinc $(\mathrm{Zn})$ and tin ( $\mathrm{Sn}$ ) can be also detected, and reasonably justified taking into account that zinc oxide $(\mathrm{ZnO})$ and tin oxide $\left(\mathrm{SnO}_{2}\right)$ were often used as opacifiers to tone down the classic shades in the case, for example, of dark blue [15].

Worth of note, the high amount of $\mathrm{Pb}$ detected for AZR5 and AZR7 shards with respect to AZR1 fragment, as testified by the high intensity of the corresponding peaks, reinforces the hypothesis of the existence, for these two pottery samples, of an engobe located between the glazed coating and the underlying ceramic paste, already hypothesized in a previous study [11].

All the XRF results obtained by handheld equipment are in excellent agreement with what already observed for the same samples through not-portable spectrometers $[11,12]$. This agreement makes us confident regarding the possibility of using portable instrumentation as advantageous tool for in situ campaigns planned in the next future.

The unambiguous identification of the aforementioned compounds was achieved at molecular scale, through the characterization of the glazed decorated surface of all the investigated pottery fragments performed by Raman spectroscopy.

Unfortunately, as far as AZR3 and AZR5 shards are concerned, the collected Raman spectra at all the available wavelengths exhibited a strong fluorescence contribution which made impossible any interpretation.

In Fig. 3 we display the Raman spectrum of the yellowish decorated surface of AZR7 in the 120-600 $\mathrm{cm}^{-}$ ${ }^{1}$ spectral range.

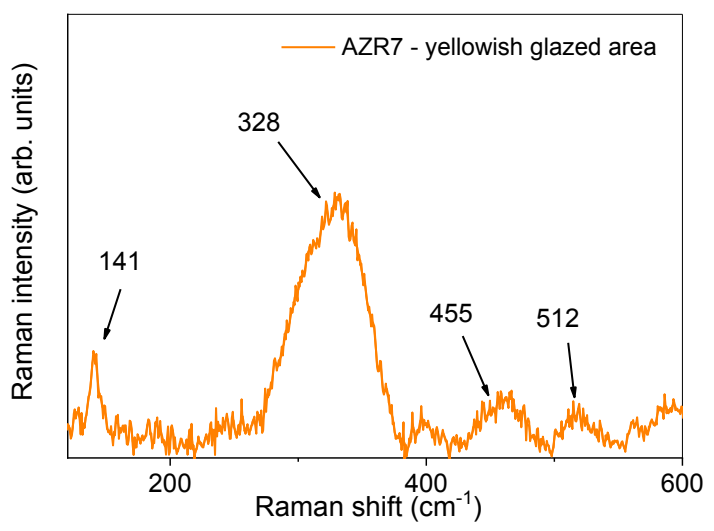

Fig. 3. Experimental Raman spectrum of the yellowish glazed surface of sample AZR7. $\lambda_{\mathrm{exc}}=785 \mathrm{~nm}$.

Based on comparison with literature [16-18], the observed features at $\sim 141 \mathrm{~cm}^{-1}, \sim 328 \mathrm{~cm}^{-1}, \sim 455 \mathrm{~cm}^{-1}$ and $\sim 512 \mathrm{~cm}^{-1}$ can be attributed to a lead-tin based 
yellow glaze of type II ( $\left.\mathrm{PbSn}_{1-\mathrm{x}} \mathrm{Si}_{\mathrm{x}} \mathrm{O}_{3}\right)$, extensively adopted during the $18^{\text {th }}-19^{\text {th }}$ century for the manufacturing of glass and glazes [19]. Its presence suggests that, during the firing process, the yellow dye was achieved by reaction of $\mathrm{Sn}$ and $\mathrm{Pb}$ oxides with $\mathrm{SiO}_{2}$, at a temperature of $\sim 900{ }^{\circ} \mathrm{C}$. This result confirms our previous estimation of the maximum firing temperature for these potteries, that turned out to be around 850-950 ${ }^{\circ} \mathrm{C}$, as indicated by SR-FTIR spectroscopy [12].

As far as AZR1 sample is concerned, Raman measurements were performed on the light-blue pigmented area and on a small area without pigment, in order to compare the external layer composition with that of the underlying ceramic paste. The collected Raman spectra are displayed in Fig. 4.

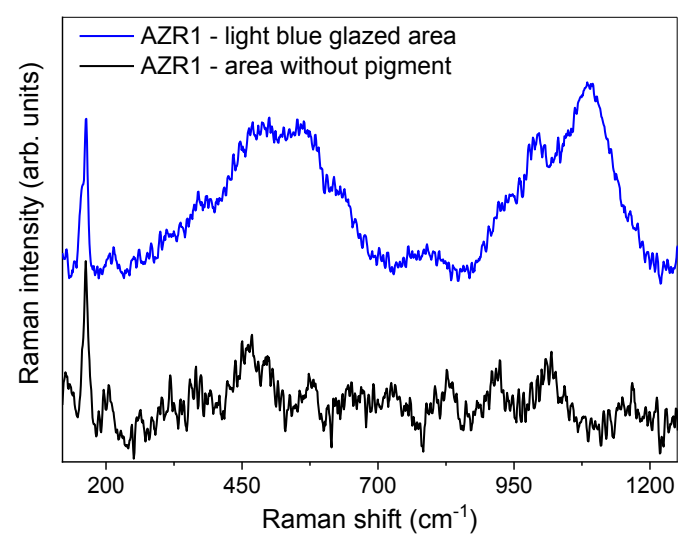

Fig. 4. Raman spectra collected on the light-blue glazed surface area and on the small area without pigment of sample AZR1. In the inset, a magnification of the low-frequency region is shown, in order to highlight the double-peak centred at $\sim 160 \mathrm{~cm}^{-1}$. $\lambda_{\text {exc }}=633 \mathrm{~nm}$.

The Raman spectrum of the light-blue pigmented area revealed, as main features, a double peak at $\sim 160$ $\mathrm{cm}^{-1}$, and two broad and complex bands in the regions $230-730 \mathrm{~cm}^{-1}$ and $\sim 870-1280 \mathrm{~cm}^{-1}$, in which several components ascribed to both pigmenting agent and glaze appear partially or, sometimes, totally overlapped. In this sense, a deconvolution procedure into symmetrical Voigt functions and curve fitting revealed helpful in order to distinguish and identify the different contributions. The results of the best-fit procedure are reported in Fig. 5.

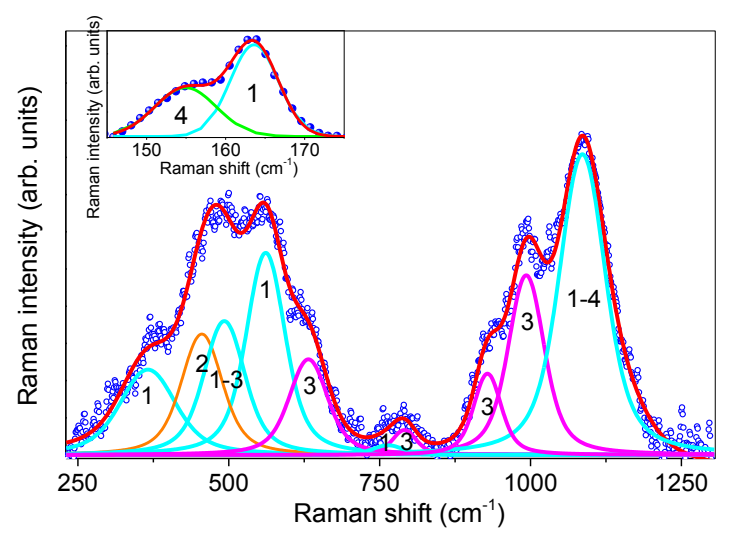

Fig. 5. Experimental Raman spectrum of the light-blue glazed surface collected in the $250-1300 \mathrm{~cm}^{-1}$ range and, in the inset, in the $145-175 \mathrm{~cm}^{-1}$ range, together with the theoretical best-fit (red line) and the deconvolution components (colored lines). 1: cuprorivaite $\left(\mathrm{CaCuSi}_{4} \mathrm{O}_{10}\right)$, 2: quartz, 3: $\mathrm{Si} / \mathrm{Sn}$-based glaze, 4 : calcite. See text for details.

From the best-fit, the Raman bands typical of cuprorivaite $\left(\mathrm{CaCuSi}_{4} \mathrm{O}_{10}\right)$ at $\sim 163 \mathrm{~cm}^{-1}, \sim 360 \mathrm{~cm}^{-1}, \sim$ $472 \mathrm{~cm}^{-1}, \sim 566 \mathrm{~cm}^{-1}$ and $\sim 1085 \mathrm{~cm}^{-1}$, have been recognized, in agreement with our previous SR-FTIR study [12], but in a complementary way and detecting low-energy excitation modes falling in a spectral range well below that of the MIR region previously investigated. Going on, calcite $\left(\mathrm{CaCO}_{3}\right)$ was also detected, through its characteristic features at $\sim 154 \mathrm{~cm}^{-1}$ and $\sim 1086 \mathrm{~cm}^{-1}$ (totally overlapped with the Raman band of cuprorivaite at $\sim 1085 \mathrm{~cm}^{-1}$ ). Moreover, the presence of quartz was testified by the two vibrational modes at $\sim 205 \mathrm{~cm}^{-1}$ (as experimentally observed and reported in Fig. 4) and $\sim 466 \mathrm{~cm}^{-1}$.

According to literature $[20,21]$ the simultaneous detection of Raman modes of cuprorivaite, calcite and quartz allows us to state that a synthetic compound know as Egyptian blue was used for the light-blue decoration in sample AZR1.

Finally, Raman bands typical of a Si/Sn-based glaze can be clearly observed at $\sim 471 \mathrm{~cm}^{-1}$ (totally overlapped with the Raman band of cuprorivaite at $\sim 472 \mathrm{~cm}^{-1}$ ), $632 \mathrm{~cm}^{-1}, \sim 777 \mathrm{~cm}^{-1}, \sim 932 \mathrm{~cm}^{-1}, \sim 997 \mathrm{~cm}^{-1}[22,23]$. These modes can be associated to both $\mathrm{SiO}_{2}$ and $\mathrm{SnO}_{2}$ oxides characterizing the glaze, supporting what already stated from the elemental composition obtained by the XRF analysis.

By looking at the Raman spectrum collected on the small area without pigment of sample AZR1 (Fig. 4), significant variations can be clearly observed. As main result, all the Raman modes observed for the blue pigmented area tend to disappear or, at least, appear strongly reduced in intensity, except for the peak around $160 \mathrm{~cm}^{-1}$. This can be justified considering that the investigated area represents a probable scrape of the specimen, which removed the most superficial glassy part of the finishing layer, still maintaining microparticles of the dye. As a consequence, due to the extremely low amount of dye micro-particles included within the area of analysis, some modes, such as that at $160 \mathrm{~cm}^{-1}$ of cuprorivaite, remained still detectable and almost unaffected in intensity and shape, whereas others are significantly lowered.

\section{Conclusions}

The glazed surface of four painted pottery shards dated back XIX century A.D., coming from the medieval archaeological context of Agsu (Azerbaijan) was here characterized at elemental and molecular level by applying a combined, multi-technique non-invasive approach, respectively based on portable X-ray fluorescence (XRF) spectroscopy and Raman spectroscopy.

The study was mainly aimed at analyzing the composition of glazes and pigments, respectively used as covering and decorations. 
The results obtained on elemental scale turned out to be in satisfactory agreement with those previously achieved on the same shards by means of not-portable instruments. This makes us confident for next in situ investigations on unmovable archaeological objects in this area, in the framework of a more comprehensive and systematic archaeometric research to be performed in Azerbaijan, up to now just at the beginning.

The data acquired at molecular level enriched our knowledge on the composition of the glazes and pigments, furnishing precious information on the manufactory procedure of these potteries.

Future multidisciplinary researches are planned, aimed at defining in detail the technological context of manufacture production, still unknown, essential prerequisite for reconstructing the communication routes in which these products circulated.

\section{References}

1. M. Ricca, G. Paladini, N. Rovella, S.A. Ruffolo, L. Randazzo, V. Crupi, B. Fazio, D. Majolino, V. Venuti, G. Galli, M.F. La Russa, Geosciences 9, 172 (2019).

2. F. Bardelli, G. Barone, V. Crupi, F. Longo, D. Majolino, P. Mazzoleni, V. Venuti, Anal. Bioanal. Chem. 399, 3147 (2011).

3. M. Bayazit, I. Işık, A. Issi, E. Genç, Appl. Clay Sci. 126, 180 (2016).

4. V. Szilágyi, J. Gyarmati, M. Tóth, H. Taubald, M. Balla, Zs. Kasztovszky, Gy. Szakmány, J. S. Am. Earth Sci. 36, 1 (2012).

5. Z. Javanshah, Sci. Cult. 4, 83 (2018).

6. A. Panagopoulou, D. Lampakis, D. Christophilos, K. Beltsios, Th. Ganetsos, Sci. Cult. 4, 27 (2018)

7. N.S.A. Rahim, Sci. Cult. 2, 19 (2016)

8. N.Ö. Fındık, A.A. Akyol, N. Sar1, Mediterr. Archaeol. Archaeom. 14, 261 (2014)

9. G. Barone, L. Bartoli, C.M. Belfiore, V. Crupi, F. Longo, D. Majolino, P. Mazzoleni, V. Venuti, J. Anal. Atom. Spectrom. 26, 1060 (2011).

10. G. Jabiev, F. Khalilli, Researches of the Agsu Archaeological Expedition in 2010-I Volume (Miras, Agsu, 2010).

11. V. Crupi, Z. Kasztovszky, F. Khalilli, M.F. La Russa, A. Macchia, D. Majolino, B. Rossi, N. Rovella, S.A. Ruffolo, V. Venuti, Int. J. Cons. Sci. 7, 901 (2016).

12. L. Torrisi, V. Venuti, V. Crupi, L. Silipigni, M. Cutroneo, G. Paladini, A. Torrisi, V. Havránek, A. Macková, M.F. La Russa, G. Birarda, L. Vaccari, A. Macchia, F. Khalilli, M. Ricca, D. Majolino, Heritage 2, 1852 (2019).

13. I.M. Bell, R.J.H. Clark, P.J. Gibbs, Spectrochim. Acta A 53, 2159 (1997).

14. B. Lafuente, R.T. Downs, H. Yang, N. Stone, The power of databases: The RRUFF project, in
Highlights in Mineralogical Crystallography (W. De Gruyter, Berlin, 2015).

15. D. Barilaro, V. Crupi, S. Interdonato, D. Majolino, V. Venuti, G. Barone, M.F. La Russa, F. Bardelli, Appl. Phys. A 92, 91 (2008).

16. K. Sakellariou, C. Miliani, A. Moressi, M. Ombelli, J. Raman Spectrosc. 35, 61 (2004).

17. I. Borgia, B.G. Brunetti, C. Miliani, C. Ricci, C. Seccaroni, A. Sgamellotti, J. Cultur. Herit. 8, 65 (2007).

18. N. Wetler, U. Schussler, W. Kiefer, J. Raman Spectrosc. 38, 113 (2007).

19. R.J.H. Clark, L. Cridland, B.M. Kariuki, K.D.M. Harris, R. Withnall, J. Chem. Soc. Dalton Trans. 16, 2577 (1995).

20. D.C. Smith, A. Barbet, J. Raman Spectrosc. 30, 319 (1999).

21. H. Berke, Chem. Soc. Rev. 36, 15 (2007).

22. L.F. Vieira Ferreira, I. Ferreira Machado, A.M. Ferraria, T.M. Casimiro, Ph. Colomban, Appl. Surf. Sci. 285, 144 (2013).

23. J. Rubio, J.L. Oteo, S. Sánchez-Cortés, A. Tamayo, F. Rubio, Application of Raman and FT-IR spectroscopy to the study of ceramic glazes, in Xth world congress on ceramic tile quality, Qualicer 183 (2008). 